\title{
$\beta$-thymosins in cancer: implications for the clinic
}
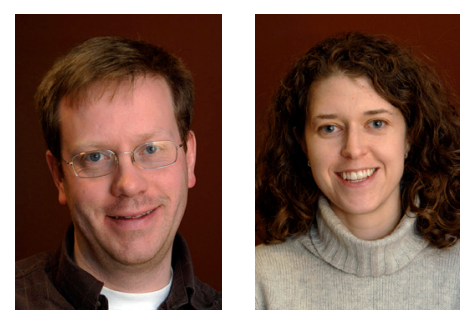

" $\beta$-thymosin-based therapies have the potential to treat the two most prevalent causes of death in the USA - cancer and cardiovascular disease. Understanding the activities and mechanisms ... will be critical for their effective clinical use."

\section{Kevin W Freeman ${ }^{\dagger} \&$ Jacqueline Banyard}

†Author for correspondence: Vascular Biology Program, Children's Hospital Boston/Harvard Medical School, 1 Blackfan Circle, Boston, MA 02115, USA = Tel.: +1 6177300268 m Fax: +1 6179192322 - kevin.freeman@childrens.harvard.edu

$\beta$-thymosins are a highly conserved family of approximately 40-44 amino acid peptides that regulate actin polymerization by binding and sequestering monomeric G-actin [1]. Actin filaments are essential for mitosis and cell motility, making their regulation an important component of cancer progression. $\beta$-thymosins are also active as extracellular mediators, where they are involved in a myriad of essential physiological responses to damage, including wound healing and hypoxic injury. During wound healing, high levels of $\beta$-thymosins are released by platelets into the wound milieu, where they promote angiogenesis, re-epithelization and moderate inflammation. In addition to regulating the cytoskeleton in cancer, the cancer microenvironment shares many features with a wound [2], making the increased $\beta$-thymosin expression observed in multiple cancers intriguing.

Currently, $\beta$-thymosins are in multiple clinical trials for treating pressure ulcers, venous stasis ulcers, epidermolysis bullosa, corneal wounds and acute myocardial infarction [3]. Two recent publications reviewing the clinical use of $\beta$-thymosins to promote wound healing and tissue repair raised the concern that $\beta$-thymosin therapy could have an untoward impact on undiagnosed cancer in these patients $[1,3]$. Indeed, patients who have been diagnosed with cancer are currently excluded from these trials. We propose that the limited risks may be outweighed by the benefits of treatment in cancer patients. Use of $\beta$-thymosins for wound healing will generally employ topical application. Furthermore, treatment for acute myocardial infarction, although systemic, would be limited in time, and therefore limited in risk of substantially promoting a cancer. However, until we better understand how extracellular $\beta$-thymosins act and whether they can promote cancer growth or metastasis, any long-term systemic treatments

may be of concern. Additionally, distinguishing between intracellular and extracellular actions of $\beta$-thymosins will be critical for development of any therapies, including anticancer therapies. Herein, we will summarize the evidence for $\beta$-thymosins facilitating the progression of cancer. Additionally, we will discuss the distinction between the extracellular and intracellular activities of these molecules and the potential role of each in cancer.

\section{${ }^{6}$ Clinical use of $\beta$-thymosins to promote wound healing and tissue repair raised the concern that $\beta$-thymosin therapy could have an untoward impact on undiagnosed cancer in these patients."}

The three $\beta$-thymosins identified in humans are $T \beta 4, T \beta 10$ and $T \beta 15$. Increased $T \beta 4$ expression has been reported in breast, ovarian and uterine cancer [4,5], and is associated with metastasis in human colorectal, renal and lung cancers [6-8]. Experimentally, T $\beta 4$ expression enhanced tumor growth and metastasis in mouse fibrosarcoma and melanoma cells $[9,10]$, and in vivo tumor growth and invasion of human colon carcinoma cells [11]. Conversely, antisense $\mathrm{T} \beta 4$ expression reduced fibrosarcoma tumor formation and metastasis [9]. Together, this shows an importance of intracellular $T \beta 4$ overexpression in cancer.

Interestingly, $T \beta 15$ shows higher affinity for actin, relative to $T \beta 4[12,13]$, while exhibiting a more restricted tissue distribution. $T \beta 15$ is a prostate cancer biomarker in human tissues, and correlates with progression and adverse patient outcome [14,15]. Current screening for prostate cancer makes use of serum prostate-specific antigen (PSA) levels, which is confounded both by false-positives due to nonmalignant prostatic

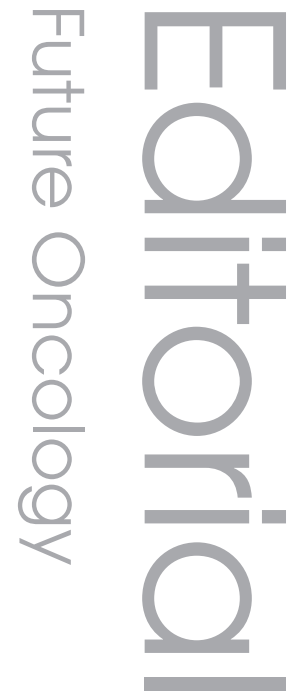

future fond $_{\text {Medicine }}$ fsg 
conditions, and false-negatives from patients with PSA levels below the current cut-off. T $\beta 15$ is a diagnostic marker for prostate cancer when assayed in human urine, and markedly improves the specificity of prostate cancer diagnosis when combined with serum PSA. Preliminary data further suggest that urinary $T \beta 15$ may be a prognostic indicator of prostate cancer patient outcome [16], as seen for T $\beta 15$ in tissues. T $\beta 15$ overexpression has been reported in several other tumor types, including breast and lung cancer [17,18]. T $\beta 15$ RNA expression also correlates with progression, metastasis and disease recurrence in additional cancers, including cancer of the brain, as recently reviewed [19]. T $\beta 15$ overexpression increases transforming activity in vitro [20], while inhibition reduces tumor cell motility, tumor cell colony formation $[14,20,21]$ and angiogenesis in the chorioallantoic membrane (CAM) assay [22].

Increased $T \beta 10$ expression has been observed in pancreatic, non-small-cell lung, renal, thyroid, colon, germ cell, breast, melanoma, uterine and ovarian cancers $[5,6,23-26]$. However, in contrast to $T \beta 4$ and $T \beta 15$, T $\beta 10$ appears to be a negative regulator of tumor development and progression. T $\beta 10$ peptide is antiangiogenic [27-29], while overexpression inhibits tumorigenesis and angiogenesis [30,31]. The contrasting roles of $\mathrm{T} \beta 10$ as a tumor suppressor, and $\mathrm{T} \beta 4$ as a tumor promoter, appear to be mediated via Ras activity, a critical modulator of tumor growth. $T \beta 10$ directly binds and inactivates Ras, while T $\beta 4$ does not [30]. Furthermore, opposing effects on tumor angiogenesis are likely mediated via $T \beta 4$ stimulation [10], and T $\beta 10$ inhibition of VEGF production [30]. The contradiction between increased expression in cancer tissues and the direct antitumorigenic effects of T $\beta 10$ might be best explained by a failed attempt at feedback inhibition. This surprising difference emphasizes the importance of distinguishing between correlative versus causal studies in understanding the role of factors in cancer progression. Additionally, this raises the exciting possibility of using therapeutic $\mathrm{T} \beta 10$ in the treatment of cancer.

What are the potential consequences of extracellular $\beta$-thymosins in cancer? It is important to separate studies based on overexpression of $\beta$-thymosins in cell lines from those in which extracellular peptide is added, since current therapy is dependent on peptide treatment [30]. One might expect a tumor-promoting activity for $T \beta 4$ peptide, due to enhanced angiogenesis accompanied by increased HIF-1 $\alpha$ stability,
VEGF production and endothelial cell recruitment $[10,32,33]$. The addition of $\mathrm{T} \beta 4$ peptide has previously been associated with increased expression of matrix metalloproteinase (MMP) -1, -2 and -9 in wounds and in different cell lines [34], and these proteins promote angiogenesis, as well as tumor invasion and metastasis.

\section{"Would modulation of $\beta$-thymosins be a treatment strategy against cancer?"}

The consequences of actin binding by intracellular $\beta$-thymosins have been best studied using $T \beta 4$. Regulation of the $T \beta 4 / G$-actin reservoir via profilin competition was recently shown to facilitate T $\beta 4$ binding to integrin-linked kinase (ILK) in endothelial cell lamellipodia. This complex recruits and activates Akt2, resulting in MMP2 production [35]. In this model, the stimulation of ILK/PINCH/Akt by the addition of exogenous $\mathrm{T} \beta 4$ was implied to have the same effects as T $\beta 4$ overexpression [36]. In contrast, systemic $\mathrm{T} \beta 4$ administration into mice with infarcted hearts increased VEGF expression and PKC activation in the cardiac tissue $24 \mathrm{~h}$ after injection. Interestingly, in this study the authors speculate that PKC is responsible for Akt phosphorylation, independent of ILK [37]. Whether this would also apply to cancer cells is unknown. Akt activation appears to be a common mediator of both intracellular and extracellular $\mathrm{T} \beta 4$ signals. Clearly, the extracellular activity of the $\beta$-thymosins leads to speculation regarding the existence of a $\beta$-thymosin receptor. Supporting evidence includes the rapid phosphorylation of c-Jun after addition of T $\beta 4$ peptide to the pancreatic cancer cell line Panc-1 [38]. However, to date, no cell-surface $\beta$-thymosin receptor has been identified.

Would modulation of $\beta$-thymosins be a treatment strategy against cancer? Altering intracellular $\beta$-thymosin expression or treatment with extracellular T $\beta 10$ peptides may both be feasible. While $\beta$-thymosins are overexpressed in many tumors, T $\beta 15$ shows the most restricted distribution in normal tissues, and may thus present a more specific target. A more difficult target may be $T \beta 4$ due to its vital role in all normal cells. However, future means of tumor-targeted therapies, coupled with knockdown strategies, for example, short interfering (si)RNAs, may circumvent this issue. In contrast to $T \beta 4$ or $T \beta 15$, the antiangiogenic activity of $T \beta 10$ peptide may lend itself to systemic treatment, targeting the extracellular tumor microenvironment. 
$\beta$-thymosins clearly have great potential to modulate wound healing. In this context, should we be concerned regarding their biological role in cancer? Importantly, $T \beta 4$ has been reported to have no role as a cancer initiator [1]. Essential to our understanding are experiments showing the effects of administering $\beta$-thymosin peptides to already established tumors. Such data have not been published. Although it would be fully expected to have an effect, to what extent this would promote tumor growth or progression would be important to understand. This information, together with better knowledge of the mechanism, may further enhance the value of $\beta$-thymosins in the clinic.

$\beta$-thymosin-based therapies have the potential to treat the two most prevalent causes of death in the USA - cancer and cardiovascular disease. Understanding the activities and mechanisms of these small potent peptides will be critical for Financial \& competing interests disclosure

The authors are senior scientists in the Zetter laboratory, which has significant financial interest in a company that looks at T $\beta 15$ as a biomarker. The authors have no other relevant affiliations or financial involvement with any organization or entity with a financial interest in or financial conflict with the subject matter or materials discussed in the manuscript apart from those disclosed.

No writing assistance was utilized in the production of this manuscript. their effective clinical use.

\section{Bibliography}

1. Goldstein AL, Hannappel E, Kleinman HK: Thymosin $\beta 4$ : actin-sequestering protein moonlights to repair injured tissues. Trends Mol. Med. 11, 421-429 (2005).

2. Dvorak HF: Tumors: wounds that do not heal. Similarities between tumor stroma generation and wound healing. N. Engl. J. Med. 315, 1650-1659 (1986).

3. Marx J: Biomedicine. Thymosins: clinical promise after a decades-long search. Science 316, 682-683 (2007).

4. Larsson LI, Holck S: Occurrence of thymosin $\beta 4$ in human breast cancer cells and in other cell types of the tumor microenvironment. Hum. Pathol. 38, 114-119 (2007).

5. Santelli G, Califano D, Chiappetta G et al.: Thymosin $\beta-10$ gene overexpression is a general event in human carcinogenesis. Am. J. Pathol. 155, 799-804 (1999).

6. Hall AK: Differential expression of thymosin genes in human tumors and in the developing human kidney. Int. J. Cancer 48, 672-677 (1991).

7. Ji P, Diederichs S, Wang Wet al.: MALAT-1, a novel noncoding RNA, and thymosin $\beta 4$ predict metastasis and survival in early-stage non-small cell lung cancer. Oncogene 22, 8031-8041 (2003).

8. Wang WS, Chen PM, Hsiao HL, Wang HS, Liang WY, Su Y: Overexpression of the thymosin $\beta-4$ gene is associated with increased invasion of SW480 colon carcinoma cells and the distant metastasis of human colorectal carcinoma. Oncogene 23, 6666-6671 (2004).

9. Kobayashi T, Okada F, Fujii N et al: Thymosin- $\beta 4$ regulates motility and metastasis of malignant mouse fibrosarcoma cells. Am. J. Pathol. 160, 869-882 (2002).

10. Cha HJ, Jeong MJ, Kleinman HK: Role of thymosin $\beta 4$ in tumor metastasis and angiogenesis. J. Natl Cancer Inst. 95 , 1674-1680 (2003).

11. Huang $\mathrm{HC}, \mathrm{Hu} \mathrm{CH}$, Tang MC et al: Thymosin $\beta 4$ triggers an epithelialmesenchymal transition in colorectal carcinoma by upregulating integrin-linked kinase. Oncogene 26, 2781-2790 (2007).

12. Eadie JS, Kim SW, Allen PG et al.: C-terminal variations in $\beta$-thymosin family members specify functional differences in actin-binding properties. J. Cell. Biochem. 77, 277-287 (2000).

13. Dhaese $\mathrm{S}$, Jonckheere V, Goethals $\mathrm{M}$ et al.: Functional and profiling studies prove that prostate cancer upregulated neuroblastoma thymosin $\beta$ is the true human homologue of rat thymosin $\beta 15$. FEBS Lett. 581, 4809-4815 (2007).

14. Bao L, Loda M, Janmey PA et al: Thymosin $\beta$ 15: a novel regulator of tumor cell motility upregulated in metastatic prostate cancer. Nat. Med. 2, 1322-1328 (1996).

15. Chakravatri A, Zehr EM, Zietman AL et al:: Thymosin $\beta-15$ predicts for distant failure in patients with clinically localized prostate cancer - results from a pilot study. Urology 55 , 635-638 (2000).

16. Hutchinson LM, Chang EL, Becker CM et al.: Use of thymosin $\beta 15$ as a urinary biomarker in human prostate cancer. Prostate 64, 116-127 (2005).

17. Gold JS, Bao L, Ghoussoub RA, Zetter BR, Rimm DL: Localization and quantitation of expression of the cell motility-related protein thymosin $\beta 15$ in human breast tissue. Mod. Pathol. 10, 1106-1112 (1997).
18. Gu YM, Li SY, Qiu XS, Wang EH: Elevated thymosin $\beta 15$ expression is associated with progression and metastasis of non-small cell lung cancer. Apmis 116, 484-490 (2008).

19. Banyard J, Hutchinson LM, Zetter BR: Thymosin $\beta$-NB is the human isoform of rat thymosin $\beta 15$. Ann. NY Acad. Sci. 1112, 286-296 (2007).

20. Abdulrahman M, Maina EN, Morris MR et al:: Identification of novel VHL targets that are associated with the development of renal cell carcinoma. Oncogene 26, 1661-1672 (2007).

21. Banyard J, Barrows C, Zetter BR: Differential regulation of human thymosin $\beta 15$ isoforms by transforming growth factor $\beta 1$. Genes Chromosomes Cancer 48, 502-509 (2009).

22. Koutrafouri V, Leondiadis L, Ferderigos N et al:: Synthesis and angiogenetic activity in the chick chorioallantoic membrane model of thymosin $\beta$-15. Peptides 24, 107-115 (2003).

23. Gu Y, Wang C, Wang Y, Qiu X, Wang E: Expression of thymosin $\beta 10$ and its role in non-small cell lung cancer. Hum. Pathol. 40, 117-124 (2009).

24. Li M, Zhang Y, Zhai Q et al:: Thymosin $\beta-10$ is aberrantly expressed in pancreatic cancer and induces JNK activation. Cancer Invest. 27, 251-256 (2009).

25. Takano T, Hasegawa $Y$, Miyauchi A et al.: Quantitative analysis of thymosin $\beta-10$ messenger RNA in thyroid carcinomas. Jpn J. Clin. Oncol. 32, 229-232 (2002).

26. Weterman MA, van Muijen GN, Ruiter DJ, Bloemers HP: Thymosin $\beta-10$ expression in melanoma cell lines and melanocytic lesions: a new progression marker for human cutaneous melanoma. Int. J. Cancer 53, 278-284 (1993).

27. Koutrafouri V, Leondiadis L, Avgoustakis K et al.: Effect of thymosin peptides on the chick chorioallantoic membrane angiogenesis 
model. Biochim. Biophys. Acta 1568, 60-66 (2001).

28. Mu H, Ohashi R, Yang H et al.: Thymosin $\beta 10$ inhibits cell migration and capillary-like tube formation of human coronary artery endothelial cells. Cell Motil. Cytoskeleton 63, 222-230 (2006).

29. Zhang T, Li X, Yu W, Yan Z, Zou H, He X: Overexpression of thymosin $\beta$-10 inhibits VEGF mRNA expression, autocrine VEGF protein production, and tube formation in hypoxia-induced monkey choroid-retinal endothelial cells. Ophthalmic Res. 41, 36-43 (2009).

30. Lee SH, Son MJ, Oh SH et al:: Thymosin $\beta(10)$ inhibits angiogenesis and tumor growth by interfering with Ras function. Cancer Res. 65, 137-148 (2005).

31. Lee SH, Zhang W, Choi JJ et al: Overexpression of the thymosin $\beta$-10 gene in human ovarian cancer cells disrupts F-actin stress fiber and leads to apoptosis. Oncogene 20, 6700-6706 (2001).

32. Malinda KM, Goldstein AL, Kleinman HK: Thymosin $\beta 4$ stimulates directional migration of human umbilical vein endothelial cells. Faseb J. 11, 474-481 (1997).

33. Oh JM, Ryoo IJ, Yang Y et al.: Hypoxia-inducible transcription factor (HIF)- $1 \alpha$ stabilization by actin-sequestering protein, thymosin $\beta-4$ (TB4) in Hela cervical tumor cells. Cancer Lett. 264, 29-35 (2008).

34. Philp D, Scheremeta B, Sibliss K et al.: Thymosin $\beta 4$ promotes matrix metalloproteinase expression during wound repair. J. Cell Physiol. 208, 195-200 (2006).

35. Fan Y, Gong Y, Ghosh PK, Graham LM, Fox PL: Spatial coordination of actin polymerization and ILK-Akt2 activity during endothelial cell migration. Dev. Cell. 16, 661-674 (2009).

36. Bock-Marquette I, Saxena A, White MD, Dimaio JM, Srivastava D: Thymosin $\beta 4$ activates integrin-linked kinase and promotes cardiac cell migration, survival and cardiac repair. Nature 432, 466-472 (2004).

37. Bock-Marquette I, Shrivastava S, Pipes GC et al.: Thymosin $\beta 4$ mediated PKC activation is essential to initiate the embryonic coronary developmental program and epicardial progenitor cell activation in adult mice in vivo. J. Mol. Cell. Cardiol. 46, 728-738 (2009).

38. Zhang Y, Feurino LW, Zhai Q et al.: Thymosin $\beta 4$ is overexpressed in human pancreatic cancer cells and stimulates proinflammatory cytokine secretion and JNK activation. Cancer Biol. Ther. 7, 419-423 (2008).

\section{Affiliations}

- Kevin W Freeman

Vascular Biology Program, Children's Hospital Boston/Harvard Medical School, 1 Blackfan Circle, Boston, MA 02115, USA Tel.: +1 6177300268

Fax: +1 6179192322

kevin.freeman@childrens.harvard.edu

- Jacqueline Banyard Vascular Biology Program, Children's Hospital Boston/Harvard Medical School, 1 Blackfan Circle, Boston, MA 02115, USA Jacqueline.banyard@childrens.harvard.edu 